\title{
Frequency of Surgical Impactions of Mandibular Third Molar in Orthodontic Patients with Different Antegonial Notching
}

\author{
Muhammad Azeem¹, Muhammad Mudassar Saleem², Zubair Hassan Awaisi³, Muhammad Imran Saleh4, Naeem \\ Murtaza $^{5}$, Syeda Rabbab Hasan ${ }^{6}$ \\ ${ }^{1}$ Assistant Professor, Department of Orthodontics, de'Montmorency College of Dentistry Lahore \\ ${ }^{2}$ Assistant Professor, Department of Oral and Maxillofacial Surgery, Islamabad Medical and Dental College \\ ${ }^{3}$ Associate Professor, Department of Orthodontics, Nishter Institute of Dentistry, Multan \\ ${ }^{4}$ Assistant Professor, Department of Oral and Maxillofacial Surgery, de'Montmorency College of Dentistry Lahore \\ ${ }^{5}$ Senior Demonstrator, Department of Orthodontics., Faisalabad Medical University \\ ${ }^{6}$ Assistant Professor, Department of Orthodontics, Islamabad Medical and Dental College
}

\section{ABSTRACT}

Background: Few studies have been reported so far on the frequency of lower third molar impactions in patients with different morphological characteristics. Our aim in this study was to find out the frequency of impacted lower third molars in orthodontic patients with different antegonial notch depths.

Material and Methods: This cross-sectional research was conducted at Orthodontics Department of Dental Section, Faisalabad Medical University, Faisalabad, and de'Montmorency College of Dentistry, Lahore, Pakistan from June 2017 to June 2019. A total of 60 orthopantomograms (OPGs) of patients with impacted lower third molars were included. The depth of antegonial notch was calculated on all the selected OPGs by measuring distance between the deepest area of the notch cavity and the tangent on the inferior border of the mandible. The patients with depth of antegonial notch of $1 \mathrm{~mm}$ or less were labeled as having shallow antegonial notch, while those with $3 \mathrm{~mm}$ or more were considered as having deep antegonial notch. Percentages and mean \pm SD were calculated for different variables. Depth of antegonial notching was compared between genders using ANOVA with P-value $<0.5$ considered as significant.

Results: Of 60 orthodontic patients, there was an equal number of male and female patients $(n=30)$. The average age of the patients was $25.5 \pm 4$ years. Overall frequency of impactions was similar in both the genders and frequency of impacted lower third molars was found to be greater in patients with deeper antegonial notches.

Conclusion: Mandibular third molar impactions were most frequent in orthodontic patients with deep antegonial notches.

Key words: Antegonial notch, Mandibular, Orthodontics, Third molars

\begin{tabular}{lll}
\hline Authors' Contribution: & Correspondence: & Article info: \\
1,2 Conception, synthesis, planning of & Muhammad Azeem & Received: July 11, 2019 \\
research and manuscript writing & Email: dental.concepts@hotmail.com & Accepted: August 9, 2019 \\
Interpretation, discussion, ${ }^{3-6}$ Active & &
\end{tabular}
participation in data collection

Data analysis.

Cite this article. Azeem M, Saleem MM, Awaisi ZH, Saleh MI, Murtaza N, Hasan SR. Frequency of Surgical Impactions of Mandibular Third Molar in Orthodontic Patients with Different Antegonial Notching. J Islamabad Med Dental Coll.2019; 8(3):112-116.

Doi: $10.35787 /$ jimdc.v8i3.343

\section{Introduction}

Mandibular third molars impactions are the most common impactions. This is when they fail to erupt in the normal functional position in the oral cavity beyond the expected developmental time, until and unless treated by orthodontics or oral surgery. ${ }^{1-2}$ There are different etiological factors reported in literature regarding impactions which include barriers in the form of soft and hard tissue, lack of arch perimeter, lack of retromolar space, lack of guidance, genetics, over-retention of primary teeth, and vertical facial morphology. ${ }^{3-7}$ The 
vertical facial pattern can influence the eruption of mandibular third molars by altering the alveolar bone density, changing the strength of orofacial muscles and by influencing the retromolar space. , $^{6,7}$

There are two types of mandibular growth patterns; vertical and horizontal. In the vertical growth pattern, mandible goes downward and backward, that leads to more bone deposition under the angle of mandible and more bone resorption at symphysis. This results in formation of notch at lower border of mandible which is known as pregonial or antegonial notching. ${ }^{8-10}$ Patients with deep antegonial notching are found to have disturbances of condylar and mandibular growth and it is more common with the patients having vertical growth pattern. ${ }^{11-13}$ Shallow antegonial notching is usually seen in patients with horizontal growth pattern where orofacial muscular forces are strong. ${ }^{12}$

Different studies have been conducted so far on finding out the frequency of lower third molar impactions and its pattern in different populations. ${ }^{9,10}$ However few studies have been reported on the frequency of lower third molar impactions in patients with different morphological characteristics. To our knowledge, this is the first study aimed at determining the frequency of impacted lower third molars in orthodontic patients with different antegonial notch depths. This will allow the orthodontists and oral surgeons to do early interceptive management of lower third molars for avoiding future impactions.

\section{Material and Methods}

This cross-sectional study was conducted at Orthodontics Department of Dental Section, Faisalabad Medical University, Faisalabad, and de'Montmorency College of Dentistry, Lahore, Pakistan from June 2017 to June 2019. Ethical approval was obtained from IRB of both institutes. The sample size was calculated with the help of $\mathrm{G}^{*}$ Power software version 3.0 .10 . Thirty patients were required to provide an $80 \%$ power with a of 0.05 and effect size of 0.582 calculated after obtaining the data from previous study. ${ }^{14}$ After taking informed consent, orthopantomograms (OPGs) with impacted lower third molars of 60 patients with age range of 25-35 years were included to record the depth of antegonial notches. The third molars with completed root formation and which were not still in its normal functional occlusion position in the mandible were declared as impacted.

Both male and female patients of ages between 25-35 years with impacted lower third molars and erupted lower second molars having good readable OPGs were included in the study. Patients with hypodontia involving lower third or second molars, un-erupted lower second molars, angulated lower second molars, history of trauma, history of orthodontic or surgical treatment, craniofacial syndromes including clefts, and lower third molars with ongoing root formation were excluded from the study.

The depth of antegonial notch was calculated on all the selected OPGs by measuring distance between the deepest area of the notch cavity to the tangent on the inferior border of the mandible. ${ }^{15,16}$ The patients with depth of antegonial notch $1 \mathrm{~mm}$ or less were considered as shallow antegonial notch patients, and those with 3 $\mathrm{mm}$ or more were considered as deep antegonial notch patients. ${ }^{15}$ (Figure 1).

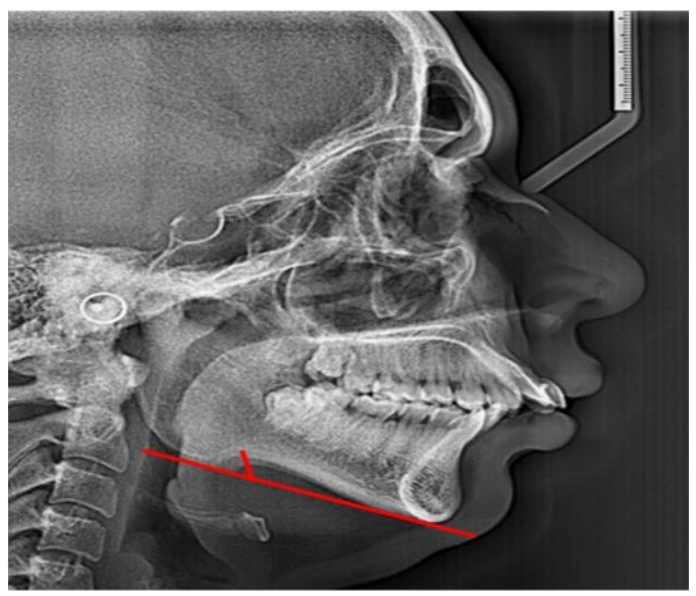

Figure 1: OPG showing antegonial notch depth

To rule out the risk of inter-examiner errors, all measurements were done by a single expert orthodontist and 25 OPGs were reevaluated later at interval of two weeks to rule out the risk of intra-examiner errors, which was found to be $7.9 \%$. Data was analyzed, age and depth of antegonial notching was presented in form of mean and standard deviation while gender and frequency of impacted lower third molars was presented as proportions and percentages. The depth of antegonial notching was compared between both the genders using ANOVA test 
and $p$ value of $<0.05$ was considered as statistically significant.

\section{Results}

Out of 60 orthodontic patients, an equal number of male and female patients were present (30 in each group) which shows that overall frequency of impaction was similar in both genders. The mean age of the patients was $25.5 \pm 4$ years. The mean age of male patients was $25.2 \pm 4.5$ years, and that of female patients was $25.7 \pm 4.4$ years. The age and gender distribution are shown in Table I.

\begin{tabular}{|l|c|c|}
\hline \multicolumn{3}{|c|}{ Table I: Age and Gender Distribution (n=60) } \\
\hline Gender & Frequency (\%) & Mean Age (Years) \\
\hline Male & $30(50)$ & $25.2 \pm 4.5$ \\
\hline Female & $30(50)$ & $25.7 \pm 4.4$ \\
\hline Total & $60(100)$ & $25.5 \pm 4.1$ \\
\hline
\end{tabular}

Patients with deep antegonial notches had greater number of impacted lower third molars (45\%) than the ones with shallow notches (26.6\%) as shown in Table II. There was no significant difference observed among male and female patients regarding antegonial notch depths in the study, please refer to table III.

\begin{tabular}{|l|c|c|}
\hline \multicolumn{3}{|c|}{$\begin{array}{c}\text { Table II: Frequency of mandibular third molar impactions in } \\
\text { different antegonial notch depths }(\mathrm{n}=60)\end{array}$} \\
\hline Antegonial depth & $\begin{array}{r}\text { Frequency of } \\
\text { Impactions }\end{array}$ & $\begin{array}{c}\text { Percentage of } \\
\text { impactions }\end{array}$ \\
\hline Normal $(1-3 \mathrm{~mm})$ & 17 & 28.3 \\
\hline Shallow $(\leq 1 \mathrm{~mm})$ & 16 & 26.6 \\
\hline Deep $(\geq 3 \mathrm{~mm})$ & 27 & 45.0 \\
\hline Total & 60 & 100.0 \\
\hline
\end{tabular}

\begin{tabular}{|l|c|c|}
\hline \multicolumn{3}{|c|}{ Table III: Gender distribution in different antegonial notch } \\
depths $(\mathbf{n}=60)$
\end{tabular}

\section{Discussion}

Previous studies have shown the frequency of lower third molar impactions in various patients with different craniofacial morphological characteristics, ${ }^{4,17-18}$ but our study is unique in observing the frequency of impacted lower third molars in orthodontic patients with different antegonial notch depths. We used OPG radiographs to find out the depth of antegonial notches, which avoided the radiation exposure of lateral cephalometric radiographs; this is in accordance with the previously conducted studies. ${ }^{15,16}$

In our study the frequency of lower third molar impaction was same in both genders. These findings are similar to results of Hatem et al, who did not find any difference in sex distribution of impacted third molars in the Libyan population. ${ }^{19}$ Kumar et al too did not find predilection towards any of the genders in third molar impaction cases in Eritrean population. ${ }^{20}$ However, there are studies with findings showing impacted third molars are more common in one of the two sexes. Ayaz and Rehman while studying the third molar impaction in the population of Peshawar, Pakistan found out that males were affected more than females. ${ }^{21}$ Similarly, Shahzad et al studied the patterns and pathologies associated with third molar impactions in Lahore, Pakistan and concluded that it was more common in females as compared to males. ${ }^{22}$

Overall, frequency of impacted lower third molars was found to be greater in patients with deep antegonial notches (45\%). This can be linked to the fact that deep antegonial notches are found more in patients with increased vertical facial pattern, which in turn leads to decreased retromolar space. The reason of decreased retromolar space is because of decreased resorption of anterior border of mandibular ramus resulting in higher number of molar impactions. ${ }^{23}$ Skadu et al. too had similar findings when they studied the crowding of teeth in relation to growth of facial skeleton. They concluded that impaction frequency of lower third molars was greater in patients with vertical growth pattern also called dolichofacial (long faced) patients. ${ }^{24}$ Nanda too while investigating patterns of vertical facial growth had similar observations about the third molar impaction. ${ }^{25}$ Breik and Grubor had comparable results when they explored the incidence of mandibular third molar impactions in various 
kinds of facial skeleton. They concluded that the incidence of impaction was less in brachyfacial (shortfaced) patients. ${ }^{26}$ They argued that these findings can be due to the reason that brachyfacial pattern leads to increased retromolar space because of increased amount of resorption of anterior border of ramus. ${ }^{26}$

We believe this is one of the pioneer studies in orthodontics to explore the frequency of impacted lower third molars in relation to antegonial notch depth. This study is a useful addition to the growing body of literature, as it will help in practicing evidence-based medicine by helping practitioners in early interceptive management of lower third molar impactions. The few limitations of our study were small sample size, lack of blinding and randomization.

\section{Conclusion}

Lower mandibular third molar impactions were found to be most frequent in orthodontic patients with deep antegonial notches.

\section{References}

1. McArdle LW, Andiappan M, Khan I, Jones J, McDonald F. Diseases associated with mandibular third molar teeth. British Dent J. 2018;224(6):434. Doi: 10.1038/sj.bdj.2018.216

2. Pilloud MA, Heim K. A Test of Age Estimation Methods on Impacted Third Molars in Males. J Forensic Sci. 2019;64(1):196-200. Doi: 10.1111/15564029.13860

3. Becker A, Chaushu S. Etiology of maxillary canine impaction: a review. Am J Orthod Dentofac Orthop. 2015;148(4):557-67.Doi: 10.1016/j.ajodo.2015.06.013

4. Santosh P. Impacted mandibular third molars: Review of literature and a proposal of a combined clinical and radiological classification. Ann Med Health Sci Res. 2015;5(4):229-34. Doi: 10.4103/2141-9248.160177

5. Niu Q, Zhang L, Dai J, Li F, Feng X. Orthodontic Management with Traction and Asymmetric Extraction for Multiple Impacted Permanent Maxillary Teeth-A Case Report. Open Dent J. 2016; 10:553. Doi: 10.2174/1874210601610010553

6. Sajnani AK. Permanent maxillary canines-review of eruption pattern and local etiological factors leading to impaction. J Invest Clin Dent. 2015;6(1):1-7. Doi: 10.1111/jicd.12067

7. Kaczor-Urbanowicz K, Zadurska M, Czochrowska E. Impacted Teeth: An Interdisciplinary Perspective. Advan Clinc Exper Med. 2016;25(3):575-85. Doi: 10.17219/acem/37451

8. Gupta S, Dhingra PS, Chatha S. A study of comparison and correlation between antegonial notch depth, symphysis morphology, and ramus morphology among different growth patterns in angle's Class II Division 1 Malocclusion. Indian J Dent Sci. 2018;10(1):21. Doi: 10.4103/IJDS.IJDS_109_17

9. Priya B, Pandian S. Assessment of ramus notch depth in different skeletal malocclusion. Drug Inven Today. 2019;12(3): 480-4

10. Kar B, Aggarwal I, Mittal S, Bhullar M, Singla D, Sharma A. Antegonial Notch and Mandibular Symphysis as indicators of Growth Pattern. Dent J Adv Stud. 2016;6(02/03):080-8. Doi: 10.1055/s-00391677777

11. Porwolik M, Porwolik K, Domagała ZA, Woźniak S, Dąbrowski P, Kacała R, Kordecki H, Chmielewski P, Faraj SA, Gworys B. Typology of the antegonial notch in the human mandible. Folia morphologica. 2015;74(3):365-71.

12. Cotrim-Ferreira FC, do Valle-Corotti KM, Lopes PD, Junqueira TH, Stocco JR. Association between respiratory pattern and mandibular morphology. Revista de Odontologia da Universidade Cidade de São Paulo. 2017;21(1):18-23.

13. Tung $K$, Lagravère MO. Skeletal and dental relationships in vertical/non-vertical growers using CBCT. Inter Orthod. 2019;17(1):123-9. Doi: 10.1016/j.ortho.2019.01.007

14. Cerqueira PR, Vasconcelos BC, Bessa-Nogueira RV. Comparative study of the effect of a tube drain in impacted lower third molar surgery. J Oral Maxillofac Surg. 2004;62(1):57-61. Doi: 10.1016/s02782391(03)00675-x

15. Lambrechts AH, Harris AM, Rossouw PE, Stander I. Dimensional differences in the craniofacial morphologies of groups with deep and shallow mandibular antegonial notching. Angle Orthod. 1996;66(4):265-72. Doi: 10.1043/00033219(1996)066<0265:DDITCM >2.3.C0;2

16. Singer $\mathrm{CP}$, Mamandras AH, Hunter WS. The depth of the mandibular antegonial notch as an indicator of mandibular growth potential. Am J Orthod Dentofacial Orthop. 1987 ;91(2):117-24. PMID: 3468794 
17. Carter $\mathrm{K}$, Worthington S. Predictors of third molar impaction: a systematic review and meta-analysis. J Dent Res. 2016;95(3):267-76. Doi: 10.1177/0022034515615857

18. Vigneswaran AT, Shilpa S. The incidence of cysts and tumors associated with impacted third molars. J Pharm Bio Sci. 2015; 7(Suppl 1): S251. Doi: 10.4103/0975-7406.155940

19. Hatem M, Bugaighis I, Taher EM. Pattern of third molar impaction in Libyan population: A retrospective radiographic study. Saudi J Dent Res. 2016;7(1):7-12. Doi: 10.1016/j.sjdr.2015.04.005

20. Kumar VR, Yadav P, Kahsu E, Girkar F, Chakraborty R. Prevalence and Pattern of Mandibular Third Molar Impaction in Eritrean Population: A Retrospective Study. J Contem Dent Prac. 2017;18(2):100-6. Doi: PMID: 28174361

21. Ayaz $H$, Rehman A. Pattern of impacted mandibular third molar in patients reporting to Department of Oral and Maxillofacial Surgery Khyber College of Dentistry Peshawar. JKCD 2012; 2 (2): 50-53
22. Shahzad M A, Marath A M, Chatha R M, Sohail A. Evaluation of patterns of mandibular third molar impactions and associated pathologies. Pak Oral Dent J. 2016: 36 (2):192-196.

23. Eroz UB, Ceylan I, Aydemir S. An investigation of mandibular morphology in subjects with different vertical facial growth patterns. Aust Orthod J. 2000; 16(1): 16-21. PMID: 11201956

24. Sakuda M, Kuroda $Y$, Wada K, Matsumoto $M$. Changes in crowding of teeth during adolescence and their relation to the growth of the facial skeleton. Trans Eur Orthod Soc.1976: 93-104.

25. Nanda SK. Patterns of vertical growth in the face. Am J Orthod Dentofac Orthop. 1988; 93(2): 103-16. Doi: 10.1016/0889-5406(88)90287-9

26. Breik 0 , Grubor D, The incidence of mandibular third molar impactions in different skeletal face types. Australian Dent J. 2008; 53(4): 320-24. Doi: 10.1111/j.1834-7819.2008.00073.x 